\title{
Weight and waist-to-hip ratio change pattern during the first five years of survival: data from a longitudinal observational Chinese breast cancer cohort
}

Yuan-Yuan Lei ${ }^{1}$, Suzanne C. Ho ${ }^{2}$, Carol Kwok ${ }^{3}$, Ashley Cheng ${ }^{3}$, Ka Li Cheung ${ }^{1}$, Roselle Lee ${ }^{1}$, Frankie Mo ${ }^{1,4}$ and Winnie $Y e o^{1,4^{*}}$

\begin{abstract}
Background: Body weight management was an important component in breast cancer survivorship care. The present study described the change patterns of body weight and waist-to-hip ratio (WHR) during the first 5 years of survival, and investigated potential factors associated with very substantial changes.

Patients and methods: Based on a longitudinal cohort with 1462 Chinese women with breast cancer, anthropometric measurements including body weight, height, waist and hip circumferences were measured by trained interviewers following standard protocol at four time-points: baseline at study entry, 18-, 36- and 60-months follow up assessments (termed as T0, T1, T2 and T3, respectively). Body height was measured at baseline and body weight at cancer diagnosis were retrieved from medical record.

Results: Compared to weight at breast cancer diagnosis, the median weight change was $-0.5 \mathrm{~kg}, 0 \mathrm{~kg},+0.5 \mathrm{~kg}$, and $+1 \mathrm{~kg}$ at T0, T1, T2 and T3, respectively. During the first 5 years of survival, the proportion of women who were obese have slightly increased. At 60 -months after diagnosis, only $14.3 \%$ of women had weight gain by $>5 \mathrm{~kg}$; and the percentage of women who had weight gain by $>10 \%$ was $10.7 \%$. Nearly half of patients had abdominal obesity at study entry, and this proportion were gradually increased to nearly $70 \%$ at 60 -months follow-up. Multivariate analysis indicated that older age, and frequent sports participation during the first 5 years of survival were related to lower risk of very substantial weight gain (> 10\%) at 60-month follow-up; patients aged 40-49 years, having $\geq 2$ comorbidities and ER negative were associated with less likelihood of very substantial WHR substantial increase (>10\%) at 60-month follow-up.

Conclusion: Weight gain was modest in Chinese breast cancer survivors during the first 5 years of survival, while central adiposity has become a contemporary public health issue. The incorporation of healthy weight and abdominal circumference patient education and management has a potential to improve cancer survivorship.
\end{abstract}

Keywords: Breast cancer, Body weight, Body mass index (BMI), Waist-to-hip ratio (WHR), Change, Chinese women

\footnotetext{
* Correspondence: winnieyeo@cuhk.edu.hk

'Department of Clinical Oncology, Prince of Wales Hospital, The Chinese University of Hong Kong, Shatin, New Territories, Hong Kong, SAR, China ${ }^{4}$ Hong Kong Cancer Institute, State Key Laboratory in Oncology in South

China, Faculty of Medicine, the Chinese University of Hong Kong, New Territories, Hong Kong, SAR, China

Full list of author information is available at the end of the article
}

(c) The Author(s). 2021 Open Access This article is licensed under a Creative Commons Attribution 4.0 International License, which permits use, sharing, adaptation, distribution and reproduction in any medium or format, as long as you give appropriate credit to the original author(s) and the source, provide a link to the Creative Commons licence, and indicate if changes were made. The images or other third party material in this article are included in the article's Creative Commons licence, unless indicated otherwise in a credit line to the material. If material is not included in the article's Creative Commons licence and your intended use is not permitted by statutory regulation or exceeds the permitted use, you will need to obtain permission directly from the copyright holder. To view a copy of this licence, visit http://creativecommons.org/licenses/by/4.0/ The Creative Commons Public Domain Dedication waiver (http://creativecommons.org/publicdomain/zero/1.0/) applies to the data made available in this article, unless otherwise stated in a credit line to the data. 


\section{Introduction}

Breast cancer is the most frequent cancer among female both in Western countries and in China $[1,2]$. An analysis from 40 years of cancer registry data showed that the incidence of breast cancer have a tremendous increase, while the mortality rate only slightly increase in urban Chinese population [3]. It indicates that a rising number of women with breast cancer would live with the disease for longer time. In Hong Kong, breast cancer has also aroused heavy disease burden in local female [4]. Breast Cancer Survivorship Care Guideline established by the American Society of Clinical Oncology (ASCO) has underscored that adoption of a healthy lifestyle as an essential element of survivorship care [5]. For such, body weight management is an important component, and ASCO recommended that primary care clinicians should counsel breast cancer survivors to achieve and maintain a healthy body weight [5].

Weight gain averaging 1.5 to $2.1 \mathrm{~kg}$ during $1-2$ year post-diagnosis has been very frequent in Caucasian women [6-9]. In Asian women, weight changes have also been observed after breast cancer diagnosis, but the results have been inconsistent, [10-13] with most of those studies being cross-sectional and involving small patient number $[10,12,13]$. The reasons for weight gain could be multifactorial. A series of factors have been suggested to be associated with weight gain, including chemotherapy, use of medication in association with chemotherapy such as dexamethasone, treatment-related amenorrhea, "stress eating" and reduced physical activity [13-16]. As weight management is an essential element in the long-term management of breast cancer survivors, there is still a need to fully investigate the pattern of weight change and explore potential risk factors associated with very substantial weight gain among Asian women with breast cancer.

The sole use of body mass index (BMI) cannot fully reflect fat distribution over body compartments [17]; therefore, waist-to-hip ratio (WHR), have been recommended for the measurement of abdominal obesity in recent decades [18]. Freedman et al. have reported that patients with breast cancer who had adjuvant chemotherapy would experience unfavorable changes in body composition without a significant weight change [19]. The pattern of WHR change after breast cancer diagnosis has not been fully illustrated. As previous study showed that Chinese and South Asian displayed a greater amount of visceral adipose tissue for a given waist circumference when compared to Europeans, the measurement of WHR in Asian may need special attention [20].

Based on longitudinal follow-up of a cohort of Chinese women with breast cancer, the present study has the following two aims: 1) to characterize the patterns of weight change from diagnosis to immediately postdiagnosis and at 18-, 36-, 60-months follow-up, and to identify potential socio-demographic, clinical and lifestyle factors associated with very substantial weight gain; 2) to describe the patterns of WHR change from immediately post-diagnosis to 18-, 36- and 60-months followup, and to identify potential factors associated with very substantial WHR increase.

\section{Patients and methods Study cohort}

The Hong Kong NTEC-KWC Breast Cancer Survival Study (HKNKBCSS) was a prospective breast cancer cohort study, initiated to investigate the associations between lifestyle factors with breast cancer recurrence and mortality [21-25]. The inclusion criteria included patients of any age, had histologically confirmed breast cancer with American Joint Committee on Cancer (AJCC) stage 0-III diagnosed no more than 12 months before study entry, [26] female gender, mentally stable, Chinese ethnicity, able to read Chinese, and did not have prior history of breast or other cancers. Between January 2011 and February 2014, 1462 eligible patients provided written informed consent and participated in the study. The study was approved by the Joint CUHK-NTEC Clinical Research Ethics Committee and the KWC Research Ethics Committee of the Chinese University of Hong Kong and the Hong Kong Hospital Authority.

Consented patients were interviewed at four timepoints: baseline at study entry (described as T0; conducted within 12-months after breast cancer diagnosis), 18-months follow-up (T1; conducted between 12 and 24 months after diagnosis), 36-months follow-up (T2; which was conducted between 30 and 42 months after diagnosis) and 60-months follow-up (T3; 54-66 months after diagnosis). A telephone call would be made prior to the planned interview, which would coincide with their scheduled clinic follow-up.

As of December 2017, the 60-months follow-up interview had been completed. Among 1462 patients who completed assessment at T0, 1310, 1162 and 1171 participants completed interviews at T1, T2 and T3, respectively (follow-up rate: 89.6, 79.5 and 80.1\%, respectively). The present study was based on the anthropometric measurements data assessed during interviews at all four time-points.

\section{Data collection}

During each follow-up interviews, patients were assessed with structured questionnaires conducted at baseline assessment, which collected socio-demographic characteristics (education level, marital status, working status and family income), reproductive history, menopausal status, active and passive smoking, alcohol use and prior 
medical history (self-reported comorbidities including but not limited to diabetes, hypertension, hyperlipidemia, chronic liver disease and chronic kidney disease). At T0 assessment, patients' menopause status was classified as two groups: pre-menopausal and postmenopausal. Patients who had their last menstrual period within 1 year were regarded as pre-menopausal. Post-menopausal was defined as patients who had a cessation of menstruation for 12 months or longer. From T0 to T3 assessment, patients' menopause status could be classified as three groups: pre-menopausal, perimenopausal and post-menopausal. Peri-menopausal was defined as pre-menopausal patients at T0 who described a change in menopause status by $\mathrm{T} 3$.

Clinical information was retrieved by reviewing hospital medical records. These included patient's age at breast cancer diagnosis, cancer characteristics [histology, AJCC stage, estrogen receptors (ER), progesterone receptors (PR) and human epidermal-growth-factor receptor 2 (HER2) status of the breast tumor] and treatment for breast cancer (type of breast surgery, details of adjuvant radiotherapy, chemotherapy and endocrine therapy).

Physical activity was measured by a validated modified Chinese Baecke questionnaire [27]. The MET code of each sport was based on the values in the Ainsworth compendium of physical activity [28]. According to the level of sports activity, patients were categorized into 3 groups as follow: never (0 MET-hours/week), rare/occasional $(<10$ MET-hours/week) and frequent $(\geq 10$ METhours/week) physical activity. The cut-off point of 10 MET-hours/week was based on the recommendations for cancer survivors $[29,30]$. Habitual dietary intake was collected by a validated and interviewer-administered food frequency questionnaire (FFQ) [31]. The average daily intake of nutrients, such as total energy, fat and other nutrients were calculated according to the Chinese Food Composition Table [32]. Meeting dietary recommendation on vegetables and fruits intake was defined as eating at least five servings (at least $400 \mathrm{~g}$ ) of nonstarchy vegetables and fruits every day according to the WCRF/AICR guidelines for cancer survivors [29]. At T0 assessment, patients were asked to recall their habitual physical activity and dietary intake in the preceding 12 months before cancer diagnosis. At T1, T2 and T3 assessments, patients were asked to report these parameters over the previous 12 months.

\section{Anthropometric measurements}

Patients who have cancer recurrence or died during the first five years did not measure their body weight in the subsequent follow-ups, and those patients did not include into the present analysis. Anthropometric measurements including body weight, height, waist and hip circumference were performed based on standard protocol. Trained interviewers measured body weight, waist and hip circumference at T0, T1, T2 and T3 assessment, respectively, and the body height was only measured at T0 assessment. Body height was measured to the nearest $0.1 \mathrm{~cm}$ with the patients in bare feet, back against the wall, heels together and eyes looking straight ahead. Body weight was measured to the nearest $0.1 \mathrm{~kg}$ with the participant in light clothing and bare feet using a TANI TA Body Fat Scale (Model BF-522, TANITA, Japan). Weight at diagnosis was collected from hospital medical records.

Body mass index (BMI) was calculated by weight $(\mathrm{kg})$ divided by the square of height $\left(\mathrm{m}^{2}\right)$. According to BMI classification of the Asia-Pacific region, patients can be categorized into 5 groups as following: underweight < $18.5 \mathrm{~kg} / \mathrm{m}^{2}$, normal $18.5-22.9 \mathrm{~kg} / \mathrm{m}^{2}$, overweight $23-$ $24.9 \mathrm{~kg} / \mathrm{m}^{2}$, obese $\geq 25 \mathrm{~kg} / \mathrm{m}^{2}$ [33]. Compared to weight at breast cancer diagnosis, absolute weight change at $\mathrm{T} 0$, T1, T2 and T3 assessment was calculated (weight at T0, T1, T2 or T3 - weight at diagnosis), and then classified into five groups: substantial loss $(>5 \mathrm{~kg})$, moderate loss $(>2 \mathrm{~kg}$ and $\leq 5 \mathrm{~kg}$ ), stable change (within $2 \mathrm{~kg}$ ), moderate gain $(>2 \mathrm{~kg}$ and $\leq 5 \mathrm{~kg})$ and substantial gain $(>5 \mathrm{~kg})$. The relative percent of weight change at T0, T1, T2 and T3 assessment was also calculated (absolute weight change at T0, T1 or T2/weight at diagnosis"100), and then classified those changes into six groups: substantial loss (> $5 \%)$, moderate loss $(>2 \%$ and $\leq 5 \%)$, stable change (within $2 \%$ ), moderate gain (>2 and $\leq 5 \%$ ), substantial gain $(5-10 \%)$ and very substantial gain $(>10 \%)$.

WHR was calculated as the ratio of waist circumference to hip circumference, which is regarded as an index of abdominal obesity [34]. World Health Organization (WHO) expert consultation defines abdominal obesity as WHR above 0.85 for women [35]; patients were grouped into two categories: without abdominal obesity $<0.85$ and with abdominal obesity $\geq 0.85$. As WHR at diagnosis were not available, the value obtained at $\mathrm{T} 0$ assessment was used as reference in the measurement of postdiagnosis WHR change. Percentage of changes between T0 assessment and T1, T2 and T3 assessment were calculated (absolute WHR change at T1, T2 or T3/WHR at T0*100), and then classified those changes into six groups: substantial decrease $(>5 \%)$, moderate decrease $(>2 \%$ and $\leq 5 \%$ ), stable change (within $2 \%$ ), moderate increase $(>2 \%$ and $\leq 5 \%)$, substantial increase $(5-10 \%)$ and very substantial increase $(>10 \%)$.

\section{Statistical analysis}

Patients' socio-demographic, clinical and lifestyle factors described as follows: continuous variables were expressed as means with standard deviation or median with range as appropriate, and categorical variables were 
summarized as patient number (n) and percentage (\%). Univariate logistic regression was performed to identify any potential factors associated with very substantial weight gain from diagnosis to T3 assessment. The potential variables with $P<0.1$ in univariate analysis were included into the multivariate logistic regression model. Similar analyses were performed to identify any potential factors associated with very substantial WHR increase from T0 to T3 assessment. All analyses were performed using SPSS 26.0; and $P$ values $<0.05$ at two-sided analysis were considered statistically significant.

\section{Results}

\section{Patients' characteristics}

A total of 1462 patients who participated in this cohort were included into this analysis. The baseline demographic, clinical and lifestyle characteristics of patients are provided in Table 1. The mean age at diagnosis was 51.9 years (SD: 9.1). The median time from diagnosis to T0 assessment was 3.2 months. Overall, $84.1 \%$ of patients had education of high school or below, $71.1 \%$ were married, $32.4 \%$ had a monthly household income of more than 30 , $000 \mathrm{HK}$ dollars and $50.6 \%$ had full-time or part-time employment. At study entry, most of patients (61.6\%) had no comorbidity and $53.5 \%$ of women were pre-menopausal. With regards to the clinical characteristics of breast tumor, majority of patients were staged as 0 -II (80.4\%), with tumor histology being invasive ductal carcinoma (83.8\%) and ER positive (72.3\%). The proportions of patients who received chemotherapy, radiotherapy and endocrine therapy were $75.2,70.6$ and $72.1 \%$, respectively.

According to the BMI criteria for Asian population, 3.6\% were underweight, $48.8 \%$ were normal weight, $20.3 \%$ were overweight and the remaining $27.3 \%$ were obese at breast cancer diagnosis. At study entry, the proportions of patients without or with abdominal obesity were 52.1 and $47.9 \%$, respectively. With regards to lifestyle factors during the proceeding 1 year before breast cancer diagnosis, about half of patients (45.6\%) never participated in sports activity, the median dietary energy intake was $1620.3 \mathrm{kcal} /$ day, median carbohydrate intake was $121.2 \mathrm{~g}(\mathrm{~g}) / 1000 \mathrm{kcal} / \mathrm{day}$, and median fat intake was $39.1 \mathrm{~g} / 1000 \mathrm{kcal} /$ day. More than half of patients $(66.1 \%)$ had vegetables and fruits $\geq 400 \mathrm{~g} /$ day. The proportions of patients who were ever smoker or ever frequent alcohol drinker were very small. The Characteristics of patients who completed follow-up at T3 were similar to the whole cohort. In addition, the characteristics of patients who were lost to follow-up at T1, T2, and T3 have been summarized in Supplementary Table 1.

\section{Distribution of patients' BMI and weight change pattern from diagnosis to $\mathrm{T} 0, \mathrm{~T} 1, \mathrm{~T} 2$ and $\mathrm{T} 3$ assessment}

The distribution of patients' BMI at each time-point (from diagnosis to 60-months post-diagnosis) were summarized in Fig. 1A. The proportions of patients being underweight were relative stable, namely 4.0, 5.3, 5.2, 4.5 and $4.5 \%$ at diagnosis, T0, T1, T2 and T3 assessment; the proportions of patients being overweight were also stable during follow-ups; the corresponding figures were 21.1, 19.7, 21.0, 21.7 and $22.1 \%$ at diagnosis, T0, T1, T2 and T3 assessment, respectively. The proportions of patients with normal BMI slightly decreased in a progressive manner during follow-ups, namely 46.4, 48.4, 45.6, 43.0 and $39.5 \%$ at diagnosis, T0, T1, T2 and T3 assessment, respectively; while the proportion of patients with obesity slightly increased, namely $28.5,26.6,28.2$, 30.9 and $33.8 \%$ at diagnosis, T0, T1, T2 and T3 assessment, respectively. In order to compare results from other countries, a sensitivity analysis was also undertaken using the WHO guideline for international use to define overweight and obesity (Supplementary Fig. 1) [36]. The proportions of patients being overweight were slightly increased during the first 5 years of survival; the corresponding figures were 22.3, 20.9, 21.2, 23.3 and 25.8\% at diagnosis, T0, T1, T2 and T3 assessment, respectively. Overall, the proportions of patients being obese were low based on WHO guideline for international use and were stable during follow-ups, being 6.2, 5.8, 7.0, 7.6 and 8.0\%.

Compared to weight at breast cancer diagnosis, the median weight change was $-0.5 \mathrm{~kg}, 0 \mathrm{~kg}, 0.5 \mathrm{~kg}$, and $1 \mathrm{~kg}$ at $\mathrm{T} 0, \mathrm{~T} 1, \mathrm{~T} 2$ and $\mathrm{T} 3$, respectively. Absolute weight change from diagnosis to $\mathrm{T} 0, \mathrm{~T} 1, \mathrm{~T} 2$ and $\mathrm{T} 3$ were summarized in Fig. 1B. Most of the women had a relative stable weight (change within $\pm 2 \mathrm{~kg}$ ) at T0, T1, T2 and T3 assessment (89.9, 55, 49.9 and $45.5 \%$, respectively) when compared to weight at diagnosis. The proportions of women who gained weight within $2-5 \mathrm{~kg}$ were 2.7 , 18.7, 20.4 and $23.4 \%$ at T0, T1, T2 and T3, respectively; and the corresponding figures for patients who had weight gain of $>5 \mathrm{~kg}$ were $0.5,4.7,9.9$ and $14.3 \%$, respectively.

Percent of weight change from diagnosis to T0, T1, $\mathrm{T} 2$ and T3 were summarized in Fig. 1C. The percentage of women who gained weight by $2-5 \%$ were 4.3 , 18.7, 19.6 and $18.1 \%$ at $\mathrm{T} 0, \mathrm{~T} 1, \mathrm{~T} 2$ and $\mathrm{T} 3$, respectively; the corresponding figures for weight gain 5$10 \%$ were $1.6,11.2,15.7$ and $20.5 \%$ at T0, T1, T2 and T3 assessment, respectively; and the proportion of patients had weight gain $>10 \%$ were relatively low, 0.3 , 3.3, 7.5 and $10.7 \%$ at T0, T1, T2 and T3 assessment, respectively.

\section{Category of WHR and change pattern from T0 to T1, T2 and T3 assessment}

The distribution of WHR categories at each follow-up were summarized in Fig. 2A. 
Table 1 Patients' demographic, clinical and lifestyle characteristics collected at T0 assessment: the whole cohort and those who completed follow-up at T3

\begin{tabular}{lll}
\hline Characteristics & $\begin{array}{l}\text { The whole cohort } \\
(\boldsymbol{n}=\mathbf{1 4 6 2}), \mathbf{n}(\mathbf{\%})\end{array}$ & $\begin{array}{l}\text { who completed } \\
\text { follow-up at T3, } \\
(\boldsymbol{n}=\mathbf{1 1 1 7}), \mathbf{n}(\mathbf{\%})\end{array}$ \\
\hline $\begin{array}{l}\text { Time from diagnosis to T0 } \\
\text { assessment, median (range), }\end{array}$ & $3.2(0.1-11.9)$ & $3.2(0.1-11.9)$ \\
\end{tabular}
months

Age at diagnosis, mean (SD), 51.9 (9.1) years

$51.9(8.8)$

Age group at diagnosis, years

$\begin{array}{lll}<40 & 150(10.3) & 111(9.5) \\ 40-49 & 468(32.0) & 383(32.7) \\ 50-59 & 552(37.7) & 444(37.9) \\ \geq 60 & 292(20.0) & 233(19.9)\end{array}$

Education level

High school or below
College or above

$1230(84.1)$

$987(84.3)$

Marital status

$$
\begin{array}{ll}
\text { Married or cohabitation } & 1039(71.1) \\
\text { Unmarried or divorced or } & 423(28.9) \\
\text { widowed } &
\end{array}
$$

$184(15.7)$

$840(71.7)$

331 (28.3)

Family income, HKD/month

$\begin{array}{lll}<15,000 & 683(46.7) & 530(45.3) \\ 15,000-30,000 & 452(30.9) & 375(32.0) \\ 30,000-50,000 & 204(14.0) & 174(14.9) \\ \geq 50,000 & 123(8.4) & 92(7.9)\end{array}$

Employment status

$\begin{array}{lll}\text { Full time } & 545(37.3) & 433(37.0) \\ \text { Part time } & 195(13.3) & 146(12.5) \\ \text { Not working } & 722(49.4) & 592(50.6)\end{array}$

Number of comorbidities

$\begin{array}{lll}0 & 901(61.6) & 726(62.0) \\ 1 & 371(25.4) & 296(25.3) \\ \geq 2 & 190(13.0) & 149(12.7)\end{array}$

Menopausal status at T0 assessment

$\begin{array}{lll}\text { Pre-menopausal } & 782(53.5) & 627(53.5) \\ \text { Post-menopausal } & 680(46.5) & 544(46.5) \\ \text { Parity } & & \\ 0 & 339(23.2) & 281(24.0) \\ 1 & 340(23.3) & 260(22.2) \\ 2 & 531(36.3) & 429(36.6) \\ \geq 3 & 252(17.2) & 201(17.2) \\ \text { AJCC stage } & & \\ 0-I & 523(35.8) & 438(37.4) \\ \text { II } & 652(44.6) & 529(45.2) \\ \text { III } & 276(18.9) & 197(16.8) \\ \text { Missing } & 11(0.8) & 7(0.6)\end{array}$

Table 1 Patients' demographic, clinical and lifestyle characteristics collected at T0 assessment: the whole cohort and those who completed follow-up at T3 (Continued)

\begin{tabular}{lll}
\hline Characteristics & $\begin{array}{l}\text { The whole cohort } \\
(\boldsymbol{n}=\mathbf{1 4 6 2}), \mathbf{n}(\%)\end{array}$ & $\begin{array}{l}\text { who completed } \\
\text { follow-up at T3, } \\
(\boldsymbol{n}=\mathbf{1 1 1 7}), \mathbf{n}(\%)\end{array}$ \\
\hline $\begin{array}{ll}\text { Histology } \\
\text { IDC }\end{array}$ & $982(83.8)$ \\
ILC & $1225(83.8)$ & $35(3.0)$ \\
DCIS & $42(2.9)$ & $70(6.0)$ \\
Others & $94(6.3)$ & $84(7.2)$ \\
ER status, \% & $101(6.9)$ & $870(74.3)$ \\
Positive & & $272(23.2)$ \\
Negative & $1057(72.3)$ & $29(2.5)$ \\
Missing & $363(24.8)$ &
\end{tabular}

PR status, \%

$\begin{array}{lll}\text { Positive } & 810(55.4) & 675(57.6) \\ \text { Negative } & 605(41.4) & 463(39.5) \\ \text { Missing } & 47(3.2) & 33(2.8)\end{array}$

HER 2 status, \%

$\begin{array}{lll}\text { Positive } & 381(26.1) & 305(26.0) \\ \text { Negative } & 966(66.1) & 786(67.1) \\ \text { Missing } & 115(7.9) & 80(6.8)\end{array}$

Type of surgery

$\begin{array}{lll}\text { Mastectomy } & 917(62.7) & 714(61.0) \\ \begin{array}{l}\text { Conservation } \\ \text { Chemotherapy, \% }\end{array} & 545(37.3) & 457(39.0) \\ \text { Yes } & 1100(75.2) & 875(74.7) \\ \text { No } & 362(24.8) & 296(25.3)\end{array}$

Radiotherapy, \%

Yes $\quad 1032(70.6) \quad 825(70.5)$

No $\quad 430(29.4) \quad 346(29.5)$

Endocrine therapy, \%

$\begin{array}{cll}\text { Yes } & 1054(72.1) & 875(74.7) \\ \text { No } & 408(27.9) & 296(25.2) \\ \text { Height, median (range), cm } & 156(137-177) & 156(137-177) \\ \text { Weight, median (range), kg } & 56.0(33.4-111.0) & 55.4(34.3-110.0)\end{array}$

$\mathrm{BMl}$ at diagnosis, $\mathrm{kg} / \mathrm{m}^{2}$

$\begin{array}{lll}\text { Underweight }(<18.5) & 53(3.6) & 51(4.4) \\ \text { Normal (18.5-22.9) } & 713(48.8) & 540(46.1) \\ \text { Overweight (23-24.9) } & 297(20.3) & 251(21.4) \\ \text { Obese ( } 225) & 399(27.3) & 329(28.1) \\ \begin{array}{l}\text { Waist circumference, } \\ \text { median (range), cm }\end{array} & 80.3(58.5-126.5) & 80.2(58.5-126.5) \\ \text { Hip circumference, } & 95.0(78.0-136.5) & 95.0(78.0-135.0)\end{array}$

median (range), $\mathrm{cm}$

WHR at T0 assessment
$<0.85$
762 (52.1)
607 (51.8) 
Table 1 Patients' demographic, clinical and lifestyle characteristics collected at T0 assessment: the whole cohort and those who completed follow-up at T3 (Continued)

\begin{tabular}{|c|c|c|}
\hline Characteristics & $\begin{array}{l}\text { The whole cohort } \\
(n=1462), \mathrm{n}(\%)\end{array}$ & $\begin{array}{l}\text { who completed } \\
\text { follow-up at T3, } \\
(n=1117), \mathrm{n}(\%)\end{array}$ \\
\hline$\geq 0.85$ & $701(47.9)$ & $564(48.2)$ \\
\hline \multicolumn{3}{|c|}{ Sports participation 1-year before diagnosis } \\
\hline Never & $666(45.6)$ & $530(45.3)$ \\
\hline Rarely/occasionally & $487(33.1)$ & $399(34.1)$ \\
\hline Frequently & $309(21.1)$ & $242(20.7)$ \\
\hline $\begin{array}{l}\text { Dietary energy intake 1-year } \\
\text { before diagnosis, median } \\
\text { (range), kcal/day }\end{array}$ & $\begin{array}{l}1620.3(551.1- \\
5787.3)\end{array}$ & $1616.6(551.1-5787.3)$ \\
\hline $\begin{array}{l}\text { Dietary carbohydrate } \\
\text { intake1-year before diagno- } \\
\text { sis, median (range), kcal/day }\end{array}$ & $121.2(56.9-191.2)$ & $121.3(56.9-191.2)$ \\
\hline $\begin{array}{l}\text { Dietary fat intake } 1 \text {-year be- } \\
\text { fore diagnosis, median } \\
\text { (range), g/1000 kcal/day }\end{array}$ & $39.1(14.2-62.7)$ & $39.0(14.2-62.7)$ \\
\hline \multicolumn{3}{|c|}{ Coffee intake 1-year before diagnosis, $\mathrm{ml} /$ week } \\
\hline$<200$ & $991(67.8)$ & $785(67.0)$ \\
\hline$\geq 200$ & $471(32.2)$ & $386(33.0)$ \\
\hline \multicolumn{3}{|c|}{ Sugar-sweetened beverage intake1-year before diagnosis, ml/week } \\
\hline$<200$ & $1178(80.6)$ & $952(81.3)$ \\
\hline$\geq 200$ & $284(19.4)$ & $219(18.7)$ \\
\hline \multicolumn{3}{|c|}{ Vegetables and fruits intake 1-year before diagnosis, g/day } \\
\hline$<400$ & $496(33.9)$ & $399(34.1)$ \\
\hline$\geq 400$ & $966(66.1)$ & $772(65.9)$ \\
\hline \multicolumn{3}{|l|}{ Ever smoking before diagnosis } \\
\hline Yes & $22(1.5)$ & $21(1.8)$ \\
\hline No & $1440(98.5)$ & $1150(98.2)$ \\
\hline \multicolumn{3}{|c|}{ Ever frequent alcohol intake before diagnosis (> 4 times/week) } \\
\hline Yes & $28(1.9)$ & $16(1.4)$ \\
\hline No & $1434(98.1)$ & $1155(98.6)$ \\
\hline
\end{tabular}

Abbreviations: $S D$ standard deviation; $H K D$ Hong Kong dollars; $B M I$ body mass index; AJCC American joint Committee on cancer; IDC invasive ductal carcinoma; ILC invasive lobular carcinoma; $D C I S$ ductal carcinoma in situ; $E R$ estrogen receptor; $P R$ progesterone receptor; HER 2 human epidermal-growthfactor receptor 2; MET metabolic equivalent of task; $g$ gram

The proportions of patients with $\mathrm{WHR}<0.85$ were $52.1,51.5,37.4$ and $30.7 \%$ at $\mathrm{T} 0, \mathrm{~T} 1, \mathrm{~T} 2$ and $\mathrm{T} 3$ assessment, respectively.

With regards to percentage of WHR change, 28.3, 21.5 and $18.8 \%$ of patients had percentage of WHR change within $\pm 2 \%$ from $\mathrm{T} 0$ to $\mathrm{T} 1, \mathrm{~T} 2$ and $\mathrm{T} 3$ assessment, respectively (Fig. 2B). The percentage of women who increased WHR by $2-5 \%$ were $18.4,19.0$ and $18.8 \%$ at T1, T2 and T3, respectively; the corresponding figures for WHR increase $5-10 \%$ were $11.4,21.1$ and $26.6 \%$ at $\mathrm{T} 1$, T2 and T3, respectively; and the proportion of patients with WHR increase $>10 \%$ were $7.7,17.5$ and $21.6 \%$ at
T1, T2 and T3, respectively. Overall, more patients had WHR increase during progressive follow-up.

\section{Analysis for risk factors associated with weight gain > $10 \%$ from diagnosis to T3 assessment}

The outcomes of univariate and multivariate analyses on factors associated with very substantial weight gain (> $10 \%)$ were summarized in Table 2 . Univariate analysis revealed that older age at breast cancer diagnosis $(P=$ $0.001)$, had $\geq 2$ comorbidities $(P=0.007)$, remained postmenopausal from T0 to T3 $(P=0.009)$, had $\geq 1$ childbirth $(P=0.009)$, frequent sports participation from $\mathrm{T} 1$ to T3 assessment $(P=0.013)$, as well as average vegetables and fruits intake from T1 to T3 assessment $\geq 400 \mathrm{~g} /$ day $(P=0.001)$ were associated with less likelihood of weight gain. However, not working $(P=0.016)$ was associated with very substantial weight gain. On multivariate analysis, older age at breast cancer diagnosis [odds ratio (OR) for patients aged $\geq 60$ years being 0.225 , 95\% confidence interval (CI): $0.073-0.697 ; P=0.010)$ and frequent sports participation from T1 to T3 assessment (OR 0.523, 95\%CI: 0.271-0.998; $P=0.049$ ) were independent factors for less likelihood of weight gain.

\section{Analysis for risk factors associated with WHR increase > 10\% from T0 to T3 assessment}

Table 3 illustrates the outcomes of univariate and multivariate analyses on factors associated with WHR increase $>10 \%$ from T0 to T3 assessment. Univariate analysis revealed that older age at breast cancer diagnosis (patients aged 40-49 years, $P=0.024$ patients aged $\geq 60$ years, $P=$ $0.016)$, had $\geq 2$ comorbidities $(P=0.001)$ and ER negative $(P=0.019)$ were associated with less likelihood of very substantial WHR increase. On multivariate analysis, older age at breast cancer diagnosis (OR for patients aged $40-49$ years $0.587,95 \%$ CI: $0.361-0.956 ; P=0.032$ ), had $\geq 2$ comorbidities (OR 0.417, 95\% CI: 0.238-0.732; $P=0.002)$ and ER negative (OR 0.624 , 95\% CI: $0.440-$ 0.886; $P=0.008$ ) were all independent factors for very substantial WHR increase.

\section{Discussion}

Based on a longitudinal breast cancer cohort, the present study prospectively measured anthropometric parameters during the first 5 years of survival. The results showed that weight gain was not common among Hong Kong women with breast cancer. Over the first 12months and at 18-months post-diagnosis, the median weight change was $-0.5 \mathrm{~kg}$ and $0 \mathrm{~kg}$, respectively. At 36 months to 60-months after diagnosis, it observed a modest weight gain with a medium value of 0.5 and $1 \mathrm{~kg}$, respectively. At 60 -months after diagnosis, only $14.3 \%$ of women had weight gain by $>5 \mathrm{~kg}$; and the percentage of women who had weight gain by $>10 \%$ was $10.7 \%$. Of 
note, nearly half of patients had abdominal obesity at study entry, and this figure gradually increased to nearly $70 \%$ at 60 -months after diagnosis. Being older and having frequent sports participation were independent protective factors for very substantial weight gain in multivariate analysis. Additionally, aged $40-49$ years at diagnosis, had $\geq 2$ comorbidities and ER negative are independently associated with less likelihood of very substantial WHR increase.

The weight change pattern in the current study were inconsistent with findings from Western countries, which have generally reported weight gain following adjuvant treatment. Goodwin et al. reported the weight change from baseline to 1 year post-diagnosis among 535 women with newly diagnosed breast cancer in Canada, and showed that about $84 \%$ of women gained weight with a mean value of $1.6 \mathrm{~kg}$ [6]. Another study which included 185 women in United States (US) with early stage breast cancer, showed that the mean weight gain was $1.5 \mathrm{~kg}, 2.7$ $\mathrm{kg}$ and $2.8 \mathrm{~kg}$ at 1 year, 2 year and 3 year after diagnosis, respectively [9]. Rock et al. examined the weight change from diagnosis to study enrollment (mean time since diagnosis: 26 months) among 1116 US breast cancer patients, showing that the mean weight gain was $2.7 \mathrm{~kg}$ and $60 \%$ of the participants reported weight gain [37]. In contrast to data from Western women, weight gain after breast cancer diagnosis among Asian women has been relatively modest. The Shanghai Breast Cancer Survival Study (SBCSS) reported that the median weight change from diagnosis to 6 , 18 and 36 months post-diagnosis were $1.0,2.0$ and $1.0 \mathrm{~kg}$, respectively; about 26,37 and $33 \%$ of gained weight by $\geq 5 \%$ at 6,18 and 36 months post-diagnosis, respectively [11]. It is noted that the magnitude of weight gain in the SBCSS was slightly greater than that obtained in the present study. Although the study design of the SBCSS was similar to the present cohort, the two studies enrolled patients diagnosed at different times; with the present study having enrolled patients who were diagnosed nearly 10 years later than the SBCSS (from 2011 to 2014). In a study of 260 Korean women with early stage breast cancer who received adjuvant treatment, the investigators reported that no weight gain was found after treatment, and the mean weight change was -0.3 and $-0.4 \mathrm{~kg}$ at $1-$ and 2 - year after treatment, respectively [10]. Another crosssectional study included 280 premenopausal women (median age at diagnosis was 41 year) with breast cancer after chemotherapy in Hong Kong and reported similar weight change pattern: the median weight gain from diagnosis to 5 years after diagnosis was $1.8 \mathrm{~kg}$, with $63.2 \%$ of women gaining weight by $>2 \%$ [13]. The varied results among studies in Asian women may be explained by difference in study design, variations in time interval for assessment since initial diagnosis, as well as diverse lifestyle habits.
Several previous studies have tried to investigate the associations between socio-demographic and clinical factors and weight change after diagnosis. In the Health, Eating, Activity and Lifestyle (HEAL) study, the results showed that postmenopausal women at diagnosis had greater weight gain than pre-menopausal women or women who had menopausal transition after diagnosis [8]. However, in the SBCSS, more weight gain was observed among women who were premenopausal during the first 6 months [11]. The present study supports the SBCSS findings that women who were pre-menopausal at study entry had higher risk of substantial weight gain than those who were postmenopausal in univariate analysis. Findings from studies in Western populations reported an association between chemotherapy and weight gain $[6,7,9,15]$. However, this finding was not confirmed in Asian population. For example, the Korean study and the SBCSS did not find a weight gain after adjuvant chemotherapy $[10,11]$. Similarly, the present study did not show chemotherapy to be associated with the risk of very substantial weight gain. On the other hand, the present study found that older age was associated with reduced risk of weight gain even in multivariate analysis, which was supported by two previous studies in Chinese women with breast cancer [11, 13].

Several studies have reported a significant decrease in physical activity during and after treatment, and this lifestyle change may be another reason for post-diagnosis weight gain $[7,38,39]$. Chen et al. explored the potential predictors of weight change in SBCSS and reported that higher exercise level was marginally related to weight loss [16]. Similar relationship was observed in the current study, higher level of physical activity was statistically associated with lower risk of very substantial weight gain in both univariate and multivariate analysis. Those findings suggested that high level of physical activity might prevent post-diagnosis weight gain. The results from SBCSS suggested that higher energy intake was related to greater weight gain [16]; while findings from the present study and Yaw et al' s study showed that total energy intake was not associated with weight change [12].

A number of reports have investigated the relationship between post-diagnosis weight gain and breast cancer prognosis, and strongly supported that post-diagnosis weight gain was related to higher risk of mortality among breast cancer survivors. In 2015, Playdon et al. systematically summarized these data, including 12 studies and a total of 23,832 breast cancer patients [40]. The meta-analysis showed that patients who gained weight by $\geq 5 \%$ was associated with increased risk of overall mortality compared with patients who maintained their body weight (defined as weight change $< \pm 5 \%$ ) [40]. However, it should be noted that evidence from Chinese 


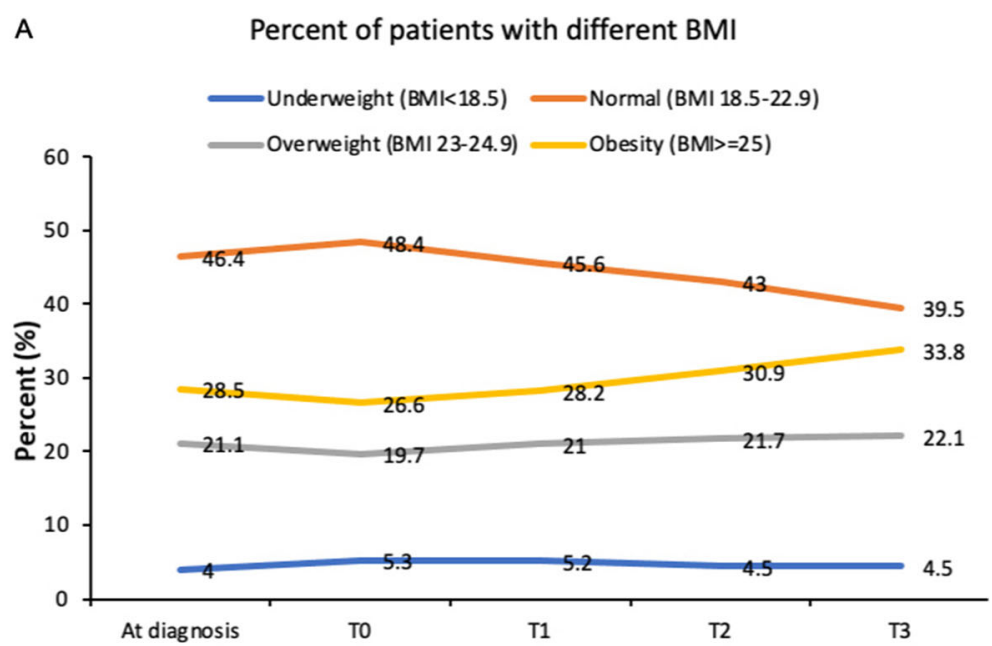

B Absoult weight change
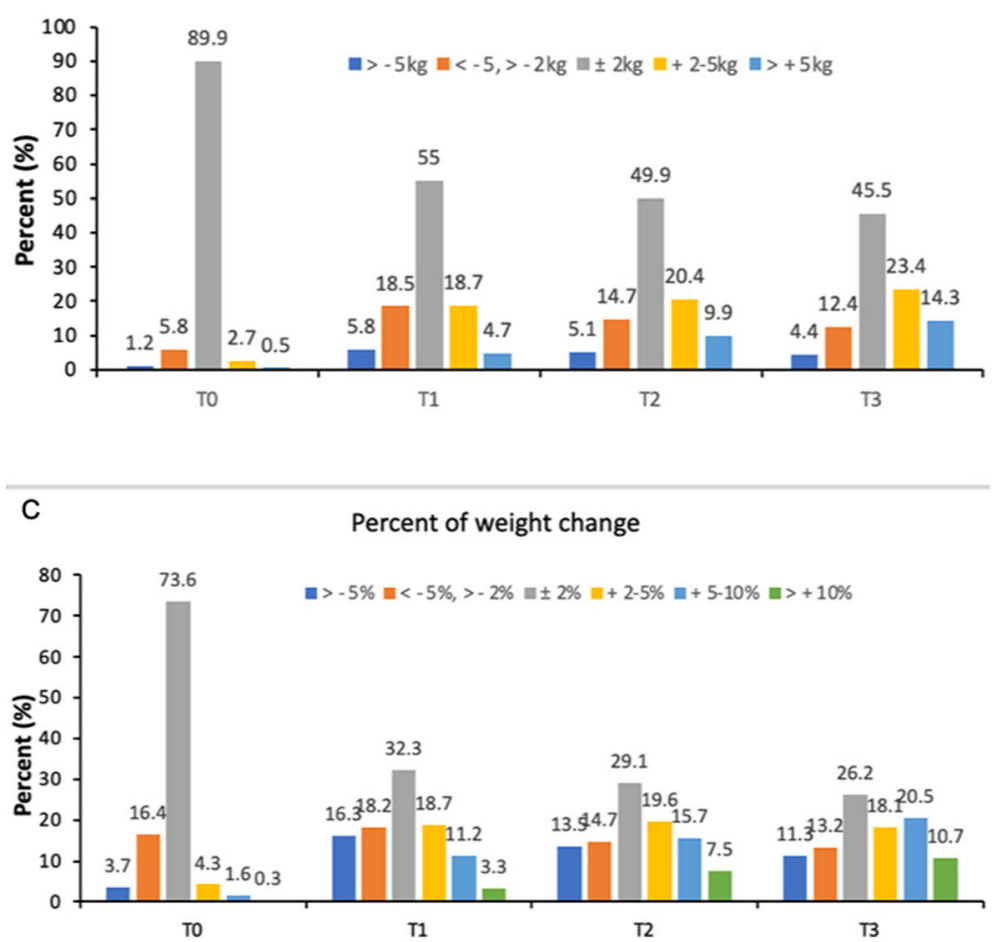

Fig. 1 Distribution of patients by BMl or weight change. A Distribution of patients by BMl at diagnosis, T1, T2 and T3 assessment; B) Distribution of patients by absolute weight change categories from diagnosis to T0, T1, T2 and T3 assessment; C) Distribution of patients by percent of weight change categories from diagnosis to T0, T1, T2 and T3 assessment. Abbreviation: BMl, body mass index

women with breast cancer has been limited, with only one study showing that women who gained $\geq 5 \mathrm{~kg}$ had higher mortality than those who maintained their weight [41].

WHR was regarded as an index for the measurement of central adiposity [35]. In general population, abdominal adipose tissue (which is positively associated with waist circumference and waist-hip ratio) is associated with a range of metabolic abnormalities, including decreased glucose tolerance, reduced insulin sensitivity and adverse lipid profiles [35]. The present study found that nearly half of women with breast cancer had central adiposity and this phenomenon is more severe as survival time increased. To our knowledge, this is the first study to describe the change pattern of WHR. Multivariate analysis showed that patients aged $40-49$ years and had 
A

\section{Distribution of WHR}

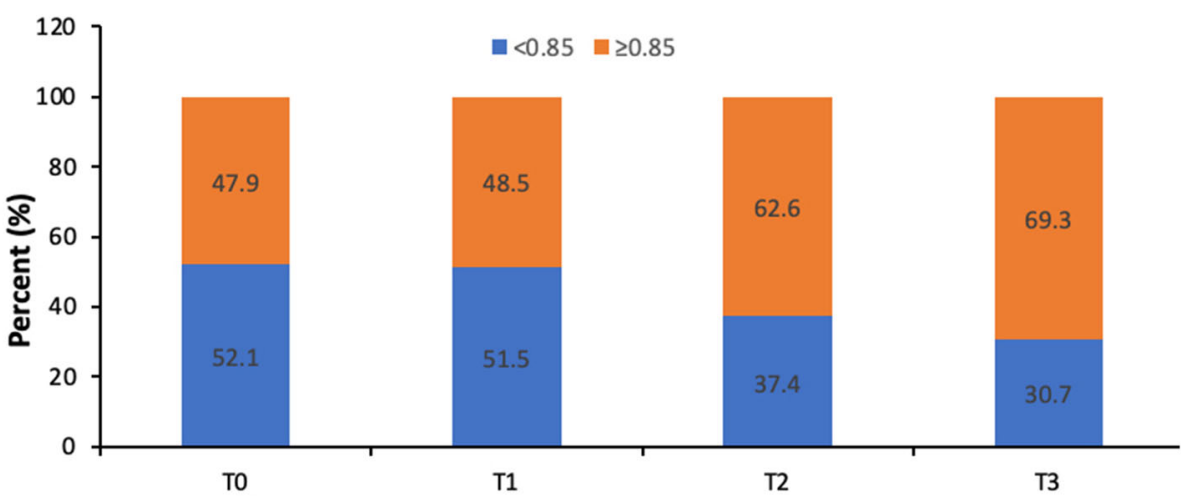

B

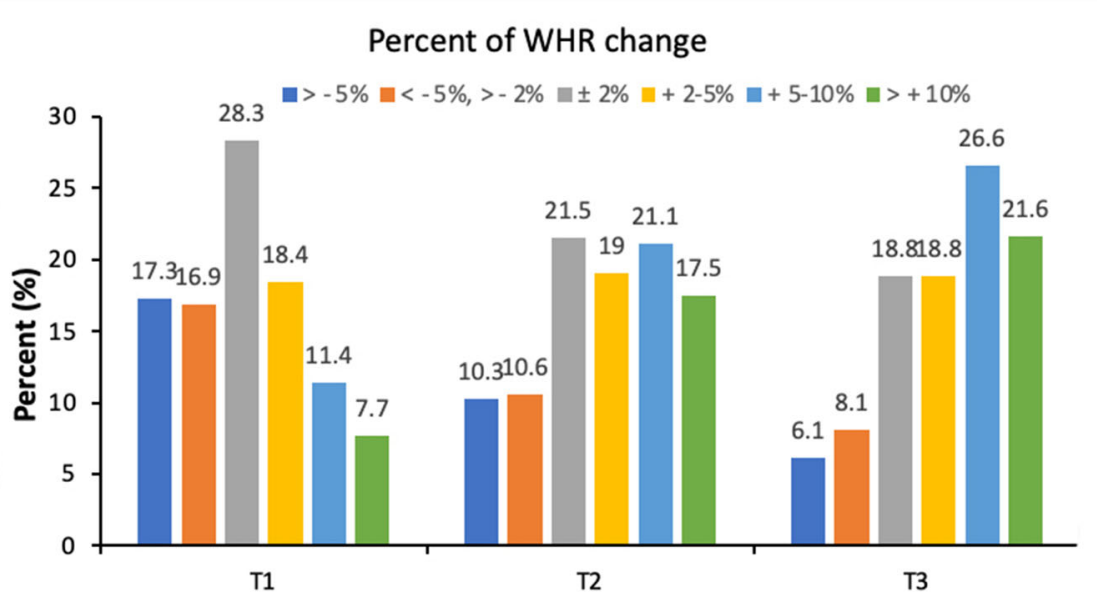

Fig. 2 Distribution of patients by WHR. A Distribution of patients' WHR categories at T0, T1, T2 and T3 assessment; $\mathbf{B}$ ) Distribution of patients by percent of WHR change categories from T0 to T1, T2 and T3 assessment. Abbreviation: WHR, waist-to-hip ratio

$\geq 2$ comorbidities were less likely to had very substantial WHR increase when compared to those aged $<40$ years and those had no comorbidity, respectively; suggesting that those patients may be more cared about abdominal obesity. Moreover, the present study suggested that patients with ER-negative disease was associated with less likelihood of very substantial WHR increase when compared to patients with ER positive; this may be related to use of adjuvant endocrine therapy, in particular, tamoxifen.

Of interests, a few studies have investigated whether central adiposity status after breast cancer diagnosis was associated with detrimental outcomes of breast cancer [42-45]. For a given BMI, it has been widely reported that Asians tend to have a higher fat percentage and a higher proportion of abdominal adiposity than western populations, [46, 47] it highlights the need to address this issue in specific ethnic groups.

This study was based on data from a longitudinal cohort study with a large sample size, with quantitatively compared the changes of body weight and WHR from immediately post-diagnosis to 5 years of survival. However, a few limitations should be noted. First, the change pattern was not compared with cancer-free women of similar age; it is, therefore, unclear whether these observed changes can be attributed to aging perse or to breast cancer and its treatment. Second, the baseline measurements of WHR were conducted within 1 year after breast cancer diagnosis; with no data captured right after diagnosis. However, the interval between diagnosis to study entry was relatively short (with median time of 3.2 months), significant WHR changes would not be expected. Third, the multivariate analysis for potential predictive factors could only be regarded as an exploratory analysis given that no clear hypothesis had been stated at priori. Fourth, as patients may experience weight loss after cancer recurrence or before death, and those patients were not included in the present analyses. As such, excluding these women who have cancer recurrence or died during the first 5 years of survival may 
Table 2 Univariate and multivariate analysis on factors associated with weight gain $>10 \%$ from diagnosis to T3 assessment, by stepwise logistic regression $(n=1171)$

\begin{tabular}{|c|c|c|c|c|c|c|}
\hline & \multicolumn{3}{|c|}{ Univariate analysis } & \multicolumn{3}{|c|}{ Multivariate analysis } \\
\hline & OR & $95 \% \mathrm{Cl}$ for $\mathrm{OR}$ & $\mathbf{P}$ & OR & $95 \% \mathrm{Cl}$ for $\mathrm{OR}$ & $\mathbf{P}$ \\
\hline Age group at diagnosis & & & 0.001 & & & 0.022 \\
\hline$<40$ & 1 & - & - & 1 & - & - \\
\hline $40-49$ & 0.848 & $0.474-1.516$ & 0.578 & 1.000 & $0.518-1.925$ & 0.996 \\
\hline $50-59$ & 0.555 & $0.306-1.007$ & 0.053 & 0.548 & $0.228-1.318$ & 0.179 \\
\hline$\geq 60$ & 0.235 & $0.104-0.528$ & $<0.001$ & 0.225 & $0.073-0.697$ & 0.010 \\
\hline \multicolumn{7}{|l|}{ Education level } \\
\hline High school or below & 1 & - & & & & \\
\hline College or above & 1.314 & $0.817-2.115$ & 0.260 & & & \\
\hline \multicolumn{7}{|l|}{ Marital status } \\
\hline Married or cohabitation & 1 & - & & & & \\
\hline Unmarried or divorced or widowed & 1.169 & $0.783-1.748$ & 0.445 & & & \\
\hline \multicolumn{7}{|l|}{ Family income, HKD/month } \\
\hline$<30,000$ & 1 & - & & & & \\
\hline$\geq 30,000$ & 1.193 & $0.778-1.828$ & 0.419 & & & \\
\hline \multicolumn{7}{|l|}{ Employment status } \\
\hline Working & 1 & - & & 1 & - & \\
\hline Not working & 1.590 & $1.088-2.323$ & 0.016 & 1.082 & $0.712-1.644$ & 0.712 \\
\hline Number of comorbidities & & & 0.026 & & & 0.160 \\
\hline 0 & 1 & - & & 1 & - & \\
\hline 1 & 0.932 & $0.609-1.428$ & 0.747 & 1.071 & $0.680-1.687$ & 0.768 \\
\hline$\geq 2$ & 0.312 & $0.134-0.727$ & 0.007 & 0.442 & $0.181-1.076$ & 0.072 \\
\hline Menopausal status from T0 to T3 assessment & & & 0.033 & & & 0.158 \\
\hline Pre-menopausal & 1 & - & & 1 & - & \\
\hline Peri-menopausal & 0.688 & $0.421-1.124$ & 0.135 & 0.865 & $0.492-1.522$ & 0.616 \\
\hline Post-menopausal & 0.521 & $0.319-0.851$ & 0.009 & 1.585 & $0.716-3.507$ & 0.256 \\
\hline \multicolumn{7}{|l|}{ Parity } \\
\hline 0 & 1 & - & & 1 & - & \\
\hline$\geq 1$ & 0.586 & $0.393-0.873$ & 0.009 & 0.771 & 0.499-1.919 & 0.242 \\
\hline AJCC stage & & & 0.810 & & & \\
\hline $0-1$ & 1 & - & & & & \\
\hline$\|$ & 0.881 & $0.586-1.327$ & 0.545 & & & \\
\hline III & 0.993 & $0.583-1.691$ & 0.980 & & & \\
\hline \multicolumn{7}{|l|}{ ER status, \% } \\
\hline Positive & 1 & & & & & \\
\hline Negative & 1.305 & $0.870-1.959$ & 0.198 & & & \\
\hline \multicolumn{7}{|l|}{ PR status, \% } \\
\hline Positive & 1 & & & & & \\
\hline Negative & 1.042 & $0.716-1.515$ & 0.831 & & & \\
\hline \multicolumn{7}{|l|}{ HER 2 status, \% } \\
\hline Positive & 1 & & & & & \\
\hline Negative & 0.932 & $0.614-1.416$ & 0.743 & & & \\
\hline
\end{tabular}

Type of surgery 
Table 2 Univariate and multivariate analysis on factors associated with weight gain $>10 \%$ from diagnosis to T3 assessment, by stepwise logistic regression $(n=1171)$ (Continued)

\begin{tabular}{|c|c|c|c|c|c|c|}
\hline & \multicolumn{3}{|c|}{ Univariate analysis } & \multicolumn{3}{|c|}{ Multivariate analysis } \\
\hline & OR & $95 \% \mathrm{Cl}$ for $\mathrm{OR}$ & $P$ & $\overline{\mathrm{OR}}$ & $95 \% \mathrm{Cl}$ for OR & $P$ \\
\hline Mastectomy & 1 & - & & & & \\
\hline Conservation & 0.898 & $0.612-1.319$ & 0.584 & & & \\
\hline \multicolumn{7}{|c|}{ Chemotherapy, \% } \\
\hline No & 1 & - & & & & \\
\hline Yes & 0.751 & $0.500-1.127$ & 0.166 & & & \\
\hline
\end{tabular}

Radiotherapy, \%

No

Yes

Endocrine therapy, \%

No

Yes

Average sports participation

from T1 to T3 assessment

$$
\begin{array}{r}
\text { Never } \\
\text { Rarely/occasionally } \\
\text { Frequently }
\end{array}
$$

Average dietary energy intake

from T1 to T3 assessment

$$
\begin{aligned}
& \leq \text { median } \\
& >\text { median }
\end{aligned}
$$

0.751

0.844

$0.568-1.255$

0.403

1

$0.562-1.290$

0.448

0.009

0.052

1

Average dietary carbohydrate intake from $\mathrm{T} 1$ to $\mathrm{T3}$

assessment, g/1000 kcal/day

$$
\begin{aligned}
& \text { smedian } \\
& >\text { median }
\end{aligned}
$$

Average dietary fat intake from $\mathrm{T} 1$ to $\mathrm{T} 3$ assessment, $\mathrm{g} / 1000$

$$
\begin{aligned}
& \text { kcal/day } \\
& \text { smedian } \\
& \text { >median }
\end{aligned}
$$

Average vegetables and fruits intake from $\mathrm{T} 1$ to $\mathrm{T} 3$ assessment, $\mathrm{g} /$ day

$\begin{array}{rcrr}<400 & 1 & - & \\ \geq 400 & \mathbf{0 . 5 6 8} & \mathbf{0 . 3 6 5 - 0 . 8 8 6} & \mathbf{0 . 0 1 3} \\ \text { to T3 assessment, } \mathrm{ml} / \text { week } & & \\ <200 & 1 & - & \\ \geq 200 & 1.067 & 0.703-1.620 & 0.760\end{array}$

Average sugar-sweetened beverage intake from $\mathrm{T} 1$ to $\mathrm{T} 3$ assessment, $\mathrm{ml} /$ week

$$
\begin{aligned}
& <200 \\
& \geq 200
\end{aligned}
$$$$
1.644
$$

0.072

1.201

$0.678-2.124$

Univariate logistic regression was performed to identify any potential factors associated with very substantial weight gain from diagnosis to T3 assessment. The potential variables with $P<0.1$ in univariate analysis were included into the multivariate logistic regression model, including age group at diagnosis, employment status, number of comorbidities, menopausal status from T0 to T3 assessment, parity, average sports participation from T1 to T3 assessment and average sugarsweetened beverage intake from $\mathrm{T} 1$ to $\mathrm{T} 3$ assessment

From T0 to T3 assessment, patients' menopause status could be classified as three groups: pre-menopausal, peri-menopausal and post-menopausal. Perimenopausal was defined as pre-menopausal patients at T0 who described a change in menopause status at T3

Abbreviations: OR odds ratio; $C l$ confidence interval; HKD Hong Kong dollars; AJCC American joint Committee on cancer; ER estrogen receptor; PR progesterone receptor; HER 2 human epidermal-growth-factor receptor 2; MET metabolic equivalent of task; $g$ gram 
Table 3 Univariate and multivariate analysis on factors associated with WHR increase $>10 \%$ from diagnosis to T3 assessment, by stepwise logistic regression $(n=1171)$

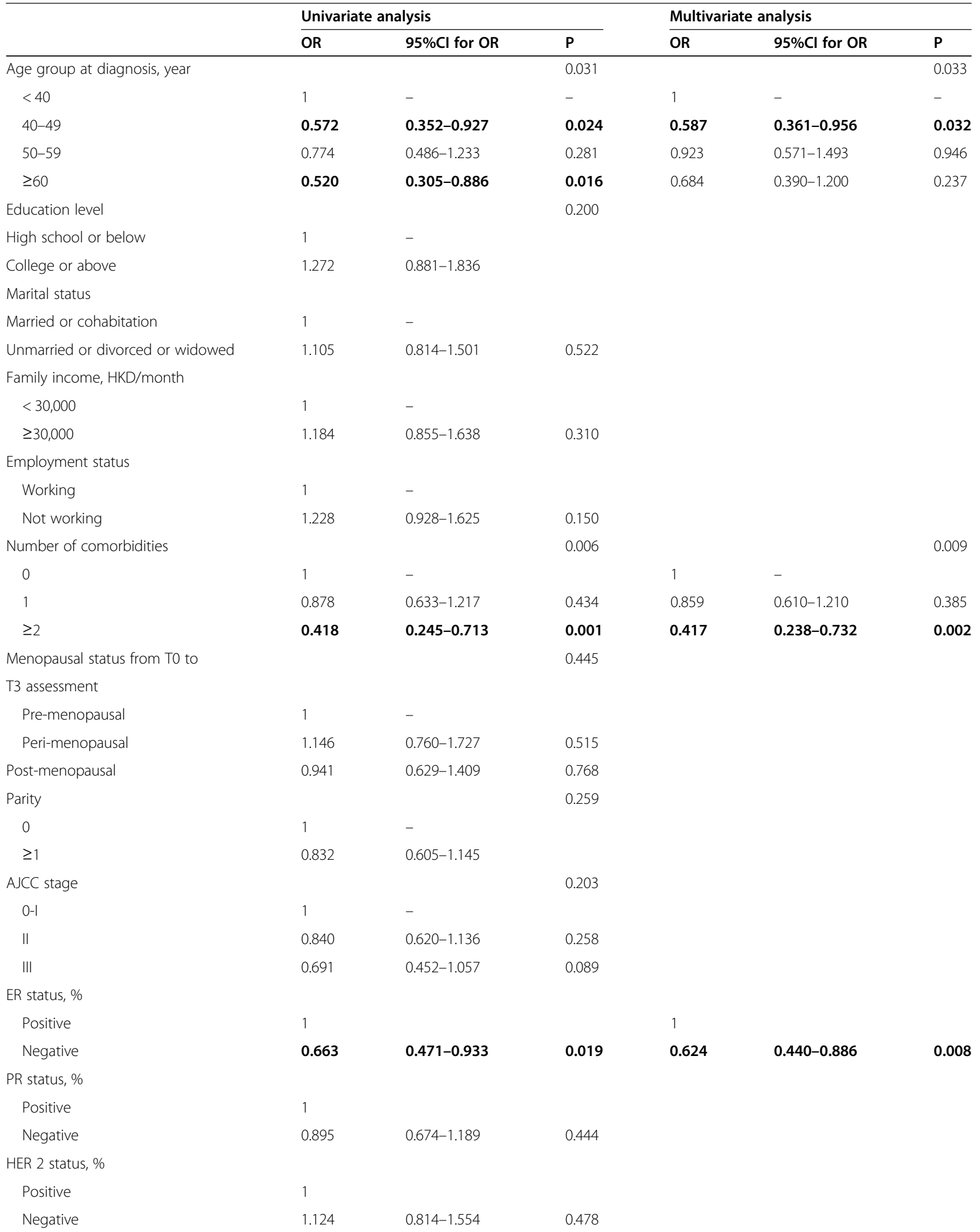


Table 3 Univariate and multivariate analysis on factors associated with WHR increase $>10 \%$ from diagnosis to T3 assessment, by stepwise logistic regression $(n=1171)$ (Continued)

\begin{tabular}{|c|c|c|c|c|c|c|}
\hline & \multicolumn{3}{|c|}{ Univariate analysis } & \multicolumn{3}{|c|}{ Multivariate analysis } \\
\hline & OR & $95 \% \mathrm{Cl}$ for $\mathrm{OR}$ & $\mathbf{P}$ & OR & $95 \% \mathrm{Cl}$ for OR & $\mathbf{P}$ \\
\hline \multicolumn{7}{|l|}{ Type of surgery } \\
\hline Mastectomy & 1 & - & & & & \\
\hline Conservation & 1.236 & $0.931-1.640$ & 0.143 & & & \\
\hline \multicolumn{7}{|l|}{ Chemotherapy, \% } \\
\hline No & 1 & - & & & & \\
\hline Yes & 0.780 & $0.571-1.065$ & 0.118 & & & \\
\hline \multicolumn{7}{|l|}{ Radiotherapy, \% } \\
\hline No & 1 & & & & & \\
\hline Yes & 1.081 & $0.794-1.472$ & 0.621 & & & \\
\hline \multicolumn{7}{|l|}{ Endocrine therapy, \% } \\
\hline No & 1 & - & & & & \\
\hline Yes & 1.229 & $0.882-1.712$ & 0.223 & & & \\
\hline Average sports participation & & & 0.655 & & & \\
\hline \multicolumn{7}{|l|}{ from $\mathrm{T} 1$ to $\mathrm{T} 3$ assessment } \\
\hline Never & 1 & - & & & & \\
\hline Rarely/occasionally & 0.843 & $0.543-1.311$ & 0.449 & & & \\
\hline Frequently & 0.942 & $0.595-1.491$ & 0.799 & & & \\
\hline \multicolumn{7}{|c|}{ Average dietary energy intake from $\mathrm{T} 1$ to $\mathrm{T} 3$ assessment } \\
\hline$\leq$ median & 1 & - & & & & \\
\hline >median & 1.010 & $0.764-1.336$ & 0.943 & & & \\
\hline
\end{tabular}

Average dietary carbohydrate intake from $\mathrm{T} 1$ to $\mathrm{T3}$

assessment, g/1000 kcal/day

\begin{tabular}{|c|c|c|c|}
\hline$\leq$ median & 1 & - & \\
\hline$>$ median & 1.052 & $0.796-1.391$ & 0.722 \\
\hline
\end{tabular}

Average dietary fat intake from $\mathrm{T} 1$ to $\mathrm{T} 3$ assessment, $\mathrm{g} / 1000$

$\begin{array}{ll}\text { kcal/day } & \\ \text { smedian } & 1 \\ \text { >median } & 1.096\end{array}$

Average vegetables and fruits intake from $\mathrm{T} 1$ to $\mathrm{T} 3$ assessment, $\mathrm{g} /$ day

$\begin{array}{llrr}<400 & 1 & - & \\ \geq 400 & 0.792 & 0.550-1.140 & 0.210\end{array}$

Average coffee intake from $\mathrm{T} 1$ to $\mathrm{T} 3$ assessment, $\mathrm{ml} /$ week

$$
\begin{array}{lll}
<200 & 1 & - \\
\geq 200 & 0.914 & 0.662-1.261
\end{array}
$$

Average sugar-sweetened beverage intake from $\mathrm{T} 1$ to $\mathrm{T} 3$

assessment, $\mathrm{ml} /$ week

$$
\begin{array}{ll}
<200 & 1 \\
\geq 200 & 0.802
\end{array}
$$

$0.489-1.316$

Univariate logistic regression was performed to identify any potential factors associated with very substantial weight gain from diagnosis to T3 assessment. The potential variables with $P<0.1$ in univariate analysis were included into the multivariate logistic regression model, including age group at diagnosis, number of comorbidities and ER status

From T0 to T3 assessment, patients' menopause status could be classified as three groups: pre-menopausal, peri-menopausal and post-menopausal. Perimenopausal was defined as pre-menopausal patients at T0 who described a change in menopause status at T3

Abbreviations: WHR waist-to-hip ratio; OR odds ratio; $C l$ confidence interval; HKD Hong Kong dollars; AJCC American joint Committee on cancer; ER estrogen receptor; $P R$ progesterone receptor; HER 2 human epidermal-growth-factor receptor 2; MET metabolic equivalent of task; $g$ gram 
lead to including more women with weight gain. Fifth, as the original study primarily aimed to investigate the associations between lifestyle factors with breast cancer recurrence and mortality, data on body fat was not collected during the assessments. As such, this report is unable to describe the patterns of body fat change. Finally, as the survival data in the present cohort was not mature enough, this study did not investigate the association between weight gain and breast cancer outcomes. Prospective follow-up is needed to further explore such association in Chinese women with breast cancer.

\section{Conclusion}

Based on a longitudinal observational cohort of Chinese female patients with early-stage breast cancer in Hong Kong, this study compared the change pattern of body weight and WHR during the first 5 years of survival, and explored the potential factors related to very substantial changes. The study identifies that breast cancer patients in Hong Kong experienced a modest weight gain over the first 5 years of survival, with only about $10 \%$ of women gained weight by $>10 \%$. WHR analysis found that nearly half of patients had central adiposity at breast cancer diagnosis, but the proportion increased to nearly $70 \%$ at 60 -months follow-up. Multivariate analyses indicated that frequent sports participation during the first 5 years of survival was significantly associated with lower risk of great weight gain after diagnosis. Weight management in breast cancer survivorship is an essential component and should be integrated into the survivorship care. Furthermore, central adiposity has become a contemporary public health issue especially for Asians, and the incorporation of healthy abdominal circumference education and management has the potential to improve the length and quality of cancer survivorship.

\section{Abbreviations}

WHR: Waist-to-hip ratio; ACS: American cancer society; ASCO: American society of clinical oncology; QoL: Quality of life; HKNKBCSS: The Hong Kong NTEC-KWC breast cancer survival study; AJCC: American joint committee on cancer; ER: Estrogen receptors; PR: Progesterone receptors; HER2: Human epidermal-growth-factor receptor 2; BMI: Body mass index; OR: Odds ratio; SBCSS: Shanghai breast cancer survival study

\section{Supplementary Information}

The online version contains supplementary material available at https://doi. org/10.1186/s12885-021-08554-5.

Additional file 1; Supplementary Table 1. The demographic, clinical and lifestyle characteristics collected at T0 assessment among patients who were loss to follow-up at T1, T2, and T3. Supplementary Fig. 1 Distribution of patients' BMl at diagnosis, T1, T2 and T3 assessment using the $\mathrm{WHO}$ guideline for international use. Abbreviation: BMI, body mass index; WHO, World Health Organization

\section{Authors' contributions}

YYL, SCH and WY designed the study. YYL and FM performed the statistical analysis. AC, CK, KLC, RL collected data. YYL, SCH and WY wrote the first draft of the manuscript, to which all authors subsequently contributed. All authors read and approved the final manuscript.

\section{Funding}

This study was funded by World Cancer Research Fund International (Grant Number WCRF 2010/249 and WCRF 2014/1197).

Availability of data and materials

All analyzed data during the current study were presented in the main manuscript. The original datasets are available from the corresponding author on reasonable request.

\section{Declarations}

Ethical approval and consent to participate

All procedures performed in studies involving human participants were in accordance with the ethical standards of the Joint CUHK-NTEC Clinical Research Ethics Committee and the KWC Research Ethics Committee of the Chinese University of Hong Kong and the Hong Kong Hospital Authority and with the 1964 Helsinki declaration and its later amendments or comparable ethical standards. The experimental protocol was also approved by the Joint CUHK-NTEC Clinical Research Ethics Committee and the KWC Research Ethics Committee of the Chinese University of Hong Kong and the Hong Kong Hospital Authority. Informed consent was obtained from all individual participants included in the study.

\section{Consent to publication}

Not Applicable.

\section{Competing interests}

The authors declare that they have no competing interests.

\section{Author details}

${ }^{1}$ Department of Clinical Oncology, Prince of Wales Hospital, The Chinese University of Hong Kong, Shatin, New Territories, Hong Kong, SAR, China. ${ }^{2}$ Division of Epidemiology, the Jockey Club School of Public Health and Primary Care, the Chinese University of Hong Kong, New Territories, Hong Kong, SAR, China. ${ }^{3}$ Department of Clinical Oncology, Princess Margaret Hospital, Hong Kong, SAR, China. ${ }^{4}$ Hong Kong Cancer Institute, State Key Laboratory in Oncology in South China, Faculty of Medicine, the Chinese University of Hong Kong, New Territories, Hong Kong, SAR, China.

Received: 17 February 2021 Accepted: 17 June 2021

Published online: 20 July 2021

References

1. Siegel RL, Miller KD, Jemal A. Cancer statistics, 2019. CA Cancer J Clin. 2019; 69(1):7-34. https://doi.org/10.3322/caac.21551.

2. Chen W, Zheng R, Baade PD, Zhang S, Zeng H, Bray F, et al. Cancer statistics in China, 2015. CA Cancer J Clin. 2016;66(2):115-32. https://doi.org/10.3322/ caac. 21338.

3. Huang Z, Wen W, Zheng Y, Gao YT, Wu C, Bao P, et al. Breast cancer incidence and mortality: trends over 40 years among women in Shanghai, China. Ann Oncol. 2016;27(6):1129-34. https://doi.org/10.1093/annonc/ mdw069.

4. Hong Kong Cancer Registry, Hospital Authority. Overview of Hong Kong Cancer Statistics of 2018. Available on the website of Hong Kong Cancer Registry. https://www3.ha.org.hk/cancereg/. Accessed May 2021.

5. Runowicz CD, Leach CR, Henry NL, Henry KS, Mackey HT, Cowens-Alvarado $\mathrm{RL}$, et al. American Cancer Society/American Society of Clinical Oncology breast Cancer survivorship care guideline. J Clin Oncol. 2016;34(6):611-35. https://doi.org/10.1200/JCO.2015.64.3809.

6. Goodwin PJ, Ennis M, Pritchard KI, McCready D, Koo J, Sidlofsky S, et al. Adjuvant treatment and onset of menopause predict weight gain after breast cancer diagnosis. J Clin Oncol. 1999;17(1):120-9. https://doi.org/10.12 00/JCO.1999.17.1.120.

7. Demark-Wahnefried W, Peterson BL, Winer EP, Marks L, Aziz N, Marcom PK, et al. Changes in weight, body composition, and factors influencing energy 
balance among premenopausal breast cancer patients receiving adjuvant chemotherapy. J Clin Oncol. 2001;19(9):2381-9. https://doi.org/10.1200/ JCO.2001.19.9.2381.

8. Irwin ML, McTiernan A, Baumgartner RN, Baumgartner KB, Bernstein L, Gilliland FD, et al. Changes in body fat and weight after a breast cancer diagnosis: influence of demographic, prognostic, and lifestyle factors. J Clin Oncol. 2005;23(4):774-82. https://doi.org/10.1200/JCO.2005.04.036.

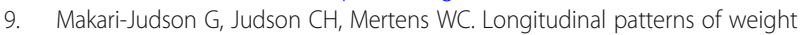
gain after breast cancer diagnosis: observations beyond the first year. Breast J. 2007;13(3):258-65. https://doi.org/10.1111/j.1524-4741.2007.00419.x.

10. Han HS, Lee KW, Kim JH, Kim SW, Kim IA, Oh DY, et al. Weight changes after adjuvant treatment in Korean women with early breast cancer. Breast Cancer Res Treat. 2009;114(1):147-53. https://doi.org/10.1007/s10549-0089984-6.

11. Gu K, Chen X, Zheng Y, Chen Z, Zheng W, Lu W, et al. Weight change patterns among breast cancer survivors: results from the Shanghai breast cancer survival study. Cancer Causes Control. 2010;21(4):621-9. https://doi. org/10.1007/s10552-009-9491-z.

12. Yaw YH, Shariff ZM, Kandiah M, Mun CY, Yusof RM, Othman Z, et al. Weight changes and lifestyle behaviors in women after breast cancer diagnosis: a cross-sectional study. BMC Public Health. 2011;11(1):309. https://doi.org/1 0.1186/1471-2458-11-309.

13. Yeo W, Mo FKF, Pang E, Suen JJS, Koh J, Loong HHF, et al. Profiles of lipids, blood pressure and weight changes among premenopausal Chinese breast cancer patients after adjuvant chemotherapy. BMC Womens Health. 2017; 17(1):55. https://doi.org/10.1186/s12905-017-0409-8.

14. Hamer J, Warner E. Lifestyle modifications for patients with breast cancer to improve prognosis and optimize overall health. CMAJ. 2017;189(7):E268e274.

15. Saquib N, Flatt SW, Natarajan L, Thomson CA, Bardwell WA, Caan B, et al. Weight gain and recovery of pre-cancer weight after breast cancer treatments: evidence from the women's healthy eating and living (WHEL) study. Breast Cancer Res Treat. 2007;105(2):177-86. https://doi.org/10.1007/ s10549-006-9442-2.

16. Chen X, Lu W, Gu K, Chen Z, Zheng Y, Zheng W, et al. Weight change and its correlates among breast cancer survivors. Nutr Cancer. 2011;63(4):538-48. https://doi.org/10.1080/01635581.2011.539316.

17. Snijder MB, van Dam RM, Visser M, Seidell JC. What aspects of body fat are particularly hazardous and how do we measure them? Int J Epidemiol. 2006;35(1):83-92. https://doi.org/10.1093/ije/dyi253.

18. Jensen MD, Ryan DH, Apovian CM, Ard JD, Comuzzie AG, Donato KA, et al. 2013 AHA/ACC/TOS guideline for the management of overweight and obesity in adults: a report of the American College of Cardiology/American Heart Association task force on practice guidelines and the Obesity Society. J Am Coll Cardiol. 2014;63(25 Pt B):2985-3023.

19. Freedman RJ, Aziz N, Albanes D, Hartman T, Danforth D, Hill S, et al. Weight and body composition changes during and after adjuvant chemotherapy in women with breast cancer. J Clin Endocrinol Metab. 2004;89(5):2248-53. https://doi.org/10.1210/jc.2003-031874.

20. Lear SA, Humphries KH, Kohli S, Chockalingam A, Frohlich JJ, Birmingham CL. Visceral adipose tissue accumulation differs according to ethnic background: results of the multicultural community health assessment trial (M-CHAT). Am J Clin Nutr. 2007;86(2):353-9. https://doi.org/10.1093/ajcn/86.2.353.

21. Lei YY, Ho SC, Cheng A, Kwok C, Cheung KL, He YQ, et al. Dietary changes in the first 3 years after breast cancer diagnosis: a prospective Chinese breast cancer cohort study. Cancer Manag Res. 2018;10:4073-84. https://doi. org/10.2147/CMAR.S168562.

22. Lei YY, Ho SC, Cheng A, Kwok C, Lee Cl, Cheung KL, et al. Adherence to the World Cancer Research Fund/American Institute for Cancer Research guideline is associated with better health-related quality of life among Chinese patients with breast Cancer. J Natl Compr Cancer Netw. 2018;16(3): 275-85. https://doi.org/10.6004/jnccn.2017.7202.

23. Lei $Y-Y$, Ho SC, Kwok C, Cheng A, Cheung KL, Lee R, et al. Longitudinal changes in sports activity from pre-diagnosis to first five years postdiagnosis: a prospective Chinese breast cancer cohort study. BMC Cancer. 2020;20(1):1013. https://doi.org/10.1186/s12885-020-07517-6.

24. Lei YY, Ho SC, Cheng A, Kwok C, Cheung KL, He YQ, et al. The association between soy isoflavone intake and menopausal symptoms after breast cancer diagnosis: a prospective longitudinal cohort study on Chinese breast cancer patients. Breast Cancer Res Treat. 2020;181(1):167-80. https://doi. org/10.1007/s10549-020-05616-3.
25. Lei YY, Ho SC, Lau TKH, Kwok C, Cheng A, Cheung KL, et al. Longitudinal change of quality of life in the first five years of survival among disease-free Chinese breast cancer survivors. Qual Life Res. 2021;30(6):1583-94. https:// doi.org/10.1007/s11136-020-02729-6.

26. Edge SB, BD CCC, Fritz AG, Greene FL, Trotti A. AJCC cancer staging manual. 7th ed. New York, NY: Springer; 2010.

27. Ho SC, Yu R, Chan S. Comparison of the modified Chinese Baecke Questionnaire with a 3-day activity diary in a Hong Kong Chinese population. Asia Pac J Public Health. 2015;27(2):Np2358-71.

28. Ainsworth BE, Haskell WL, Herrmann SD, Meckes N, Bassett DR Jr, TudorLocke C, et al. 2011 compendium of physical activities: a second update of codes and MET values. Med Sci Sports Exerc. 2011;43(8):1575-81. https://doi. org/10.1249/MSS.0b013e31821ece12.

29. World Cancer Research Fund/American Institute for Cancer Research. Food, nutrition, physical activity, and the prevention of Cancer: a global perspective. Washington, DC: AICR; 2007.

30. Rock CL, Doyle C, Demark-Wahnefried W, Meyerhardt J, Courneya KS, Schwartz $\mathrm{AL}$, et al. Nutrition and physical activity guidelines for cancer survivors. CA Cancer J Clin. 2012;62(4):243-74. https://doi.org/10.3322/caac.21142.

31. Zhang CX, Ho SC. Validity and reproducibility of a food frequency questionnaire among Chinese women in Guangdong province. Asia Pac J Clin Nutr. 2009;18(2):240-50.

32. Yang Y-X, Wang G-Y, Pan X-C. China Food Composition 2002. Beijing, China: Peking University Medical Press; 2002.

33. WHO/IASO/IOTF. The Asia-pacific perspective: redefining obesity and its treatment. Melbourne, Australia: Health Communications Australia; 2000.

34. Alberti KG, Zimmet PZ. Definition, diagnosis and classification of diabetes mellitus and its complications. Part 1: diagnosis and classification of diabetes mellitus provisional report of a WHO consultation. Diabet Med. 1998;15(7):539-53. https://doi.org/10.1002/(SICI)1096-9136(199807)15:7<53 9::AID-DIA668>3.0.CO;2-S

35. World Health Organization. Waist circumference and waist-hip ratio: a report of a WHO expert consultation, Geneva, 8-11 December 2008. Geneva: 2011.

36. Obesity WHOCo, World Health $\mathrm{O}$. Obesity : preventing and managing the global epidemic : report of a WHO consultation. In. Geneva: World Health Organization; 2000.

37. Rock CL, Flatt SW, Newman V, Caan BJ, Haan MN, Stefanick ML, et al. Factors associated with weight gain in women after diagnosis of breast cancer. Women's healthy eating and living study group. J Am Diet Assoc. 1999; 99(10):1212-21. https://doi.org/10.1016/S0002-8223(99)00298-9.

38. Demark-Wahnefried W, Hars V, Conaway MR, Havlin K, Rimer BK, McElveen $\mathrm{G}$, et al. Reduced rates of metabolism and decreased physical activity in breast cancer patients receiving adjuvant chemotherapy. Am J Clin Nutr. 1997;65(5):1495-501. https://doi.org/10.1093/ajcn/65.5.1495.

39. Irwin ML, Crumley D, McTiernan A, Bernstein L, Baumgartner R, Gilliland FD, et al. Physical activity levels before and after a diagnosis of breast carcinoma: the health, eating, activity, and lifestyle (HEAL) study. Cancer. 2003;97(7):1746-57. https://doi.org/10.1002/cncr.11227.

40. Playdon MC, Bracken MB, Sanft TB, Ligibel JA, Harrigan M, Irwin ML. Weight gain after breast cancer diagnosis and all-cause mortality: systematic review and meta-analysis. J Natl Cancer Inst. 2015;107(12):djv275.

41. Chen X, Lu W, Zheng W, Gu K, Chen Z, Zheng Y, et al. Obesity and weight change in relation to breast cancer survival. Breast Cancer Res Treat. 2010; 122(3):823-33. https://doi.org/10.1007/s10549-009-0708-3.

42. Tryggvadottir $H$, Ygland Rödström M, Markkula A, Kenéz X, Isaksson K, Borgquist $S$, et al. The impact of body size changes on recurrence risk depends on age and estrogen receptor status in primary breast cancer. Cancer Causes Control. 2019;30(11):1157-70. https://doi.org/10.1007/s10552-019-01227-6.

43. Sun $X$, Nichols HB, Robinson W, Sherman ME, Olshan AF, Troester MA. Postdiagnosis adiposity and survival among breast cancer patients: influence of breast cancer subtype. Cancer Causes Control. 2015;26(12):1803-11. https:// doi.org/10.1007/s10552-015-0673-6.

44. Chen HL, Ding A, Wang ML. Impact of central obesity on prognostic outcome of triple negative breast cancer in Chinese women. SpringerPlus. 2016;5(1):594. https://doi.org/10.1186/s40064-016-2200-y.

45. George SM, Bernstein L, Smith AW, Neuhouser ML, Baumgartner KB, Baumgartner RN, et al. Central adiposity after breast cancer diagnosis is related to mortality in the health, eating, activity, and lifestyle study. Breast Cancer Res Treat. 2014;146(3):647-55. https://doi.org/10.1007/s10549-014-3 048-x. 
46. Wang J, Thornton JC, Burastero S, Shen J, Tanenbaum S, Heymsfield SB, et al. Comparisons for body mass index and body fat percent among Puerto Ricans, blacks, whites and Asians living in the New York City area. Obes Res. 1996:4(4):377-84. https://doi.org/10.1002/j.1550-8528.1996.tb0024 5.x.

47. Mandavilli A, Cyranoski D. Asia's big problem. Nat Med. 2004;10(4):325-7. https://doi.org/10.1038/nm0404-325.

\section{Publisher's Note}

Springer Nature remains neutral with regard to jurisdictional claims in published maps and institutional affiliations.

Ready to submit your research? Choose BMC and benefit from:

- fast, convenient online submission

- thorough peer review by experienced researchers in your field

- rapid publication on acceptance

- support for research data, including large and complex data types

- gold Open Access which fosters wider collaboration and increased citations

- maximum visibility for your research: over $100 \mathrm{M}$ website views per year

At $\mathrm{BMC}$, research is always in progress.

Learn more biomedcentral.com/submissions 